minants of reinforcement in the rat. Physiology \& Behavior, 9, 705-716.

Collier, G. H., Johnson, D. F., Hill, W. L., \& Kaufman, L. W. (1986). The economics of the law of effect. Journal of the Experimental Analysis of Behavior, 46, 113-136.

Ferster, C. B., \& SkINNER, B. F. (1957). Schedules of reinforcement. New York: Appleton-Century-Crofts.

Hursh, S. R. (1984). Behavioral economics. Journal of the Experimental Analysis of Behavior, 42, 435-452.
Jensen, G. D. (1963). Preference for bar-pressing over " free-loading" as a function of number of rewarded presses. Journal of Experimental Psychology, 65, 451-454.

Kopp, J., Bourland, G., TARTE, R. D., \& Vernon, C. R. (1976). Acquisition of bar-pressing in non-deprived rats. Psychological Record, 26, $49-54$

(Manuscript received April 28, 1990.)

\title{
Announcement
}

\section{Human Behavior Bibliography Project}

Readers are invited to participate in a project for the compilation of a Bibliography of Human Behavior.

The project will collect titles from numerous disciplines in which human behavior is researched according to methods of the biological sciences. Some main fields to be covered are Human Evolution, Cultural Evolution (including Prehistory), Human Biology, Behavior Genetics, Ethology, Sociobiology, Biological Anthropology, Social Psychology, Political Science, Experimental Psychology (learning theory), Endocrinology, Brain Sciences, and Psychopathology.

The professional associations sponsoring the project are the Australian Society for Human Biology, the European Sociobiological Society, the Association for Politics and the Life Sciences, and the International Society for Human Ethology.

The bibliography will have a Name and Subject index. Pro-Cite ${ }^{\mathrm{Th}}$ is the project database application. It is expected that the published bibliography will be available in book form and on disk, thus giving users great flexibility.

Because of the bibliography's broad scope, standard methods of title search are being augmented by solicitation of titles. If you choose to submit titles, please use the following format:

- Place your 10 most significant publications at the beginning of the list.

- Write journal titles out in full. For books, please indicate both the publisher's name and place of publication.

- After each title, enter three key words for use in the subject index.

- Titles published after 1980 are preferred. Titles prior to 1980 should be particularly significant.

- Include "in press" publications.

The estimated duration of the project is 2 years. To facilitate inputting, please submit at your earliest convenience.

Submissions should be made to Bibliography Project, Griffith University, Brisbane 4111, Australia (E-Mail humcaton@pegasus.itc.gu.oz.aub). 